\title{
Insects as food: Illuminating the food neophobia and socio-cultural dynamics of insect consumption in Uganda
}

\author{
Solomon Olum ${ }^{1}$, Joshua Wesana ${ }^{2}$, Justine Mawadri ${ }^{1}$, Joanitar Kizza Nakiranda ${ }^{1}$, Walter \\ Odongo $* 3$ \\ ${ }^{1}$ Department of Food Science and Postharvest Technology, Faculty of Agriculture and \\ Environment Gulu University, P.O Box 166, Gulu, Uganda \\ ${ }^{2}$ Food and Markets Department, Natural Resources Institute, University of Greenwich, \\ Chatham, United Kingdom \\ ${ }^{3}$ Department of Rural Development and Agribusiness, Faculty of Agriculture and \\ Environment Gulu University, P.O Box 166, Gulu, Uganda \\ *Corresponding author \\ Walter Odongo \\ odongo78@gmail.com
}

Tel: +256777036100

\begin{abstract}
Entomophagy presents the most viable and sustainable meat alternative to feed the everincreasing world population as insects are highly nutritious. However, the potential of edible insects' consumption is constrained by consumers' fear towards novel or unfamiliar foods (food neophobia), which tends to be high for insects. This paper assessed the influence of food neophobia and socio-cultural factors on the consumption and consumers' willingness to consume three edible insects in Uganda (the long-horned grasshoppers, the flying African termites and the wingless red termites). Data were collected from 310 edible insects' consumers from two culturally different regions in Uganda. Results show that culture and familiarity with edible insects are important determinants of edible insects' consumption. Consumers with high levels of food neophobia were less likely to consume edible insects that were unfamiliar to them. Much as the population exhibited high levels of food neophobia, neophobia was not a significant predictor of future edible insect consumption. In addition, personal characteristics like education and age influenced both the level of food neophobia and consumption of insects. Therefore, consumption of edible insect should be promoted, keeping in mind specific cultural contexts and familiarity of specific edible insects among potential consumers. Improving knowledge of consumers about edible insects and their nutritional benefits could also lower their levels of food neophobia and improve willingness to consume insects.
\end{abstract}

Keywords: Edible insects, food neophobia, Ruspolia differens, termites, culture, Uganda 


\section{Introduction}

As the world population increases, there is need for food production to keep pace with the increasing demand for food (United Nations 2017). However, sustainable food production remains a challenge as agricultural land becomes more scarce (Van Huis et al. 2013). Of particular interest is the increasing demand and consumption of meat due to the increase in incomes, urbanization and diet diversification, both in developing and developed countries (Tilman and Clark 2014). Livestock production poses the greatest risk to the environment as it accounts for over $18 \%$ of all greenhouse gas emissions, in addition to requiring a lot of space and feeds (Clune et al. 2017; Steinfeld et al. 2006; Van Huis et al. 2013). Consequently, there is need to look at animal meat alternatives as ways of securing healthy consumption and ensuring sustainable production (Vanhonacker et al. 2013).

Insect consumption (entomophagy) has been fronted as a good alternative to animal meat. Entomophagy offers many advantages to animal meat consumption. First, insects have high feed-conversion ratios compared to livestock (Collavo et al. 2005; Van Huis et al. 2013). Second, they require limited space for production and thus, pose a lower environmental effect compared to livestock production (Lombardi et al. 2019; Smetana et al. 2015). Third, insects grow faster and are highly prolific, multiplying in large numbers in short time periods (Coleman 2016; Kelemu et al. 2015; Rumpold and Schlüter 2013). Forth, insects have considerable nutritive values, being comparatively rich in protein, minerals, fatty acids and vitamins (Coleman 2016; Kinyuru et al. 2013; Roos and Van Huis 2017; Rumpold and Schlüter 2013).

Despite the spread in entomophagy in many countries and cultures, many consumers are still afraid to consume insects or insect foods. For communities that do not traditionally consume insects, they consider entomophagy a backward and rural practice by people of low socioeconomic class (Palmieri et al. 2019; Van Huis et al. 2013). However, for insect eating communities, the type of edible insects consumed usually vary from one community to another. As such, consumers tend to be familiar with and hence eat an edible insect they are accustomed to, and refrain from consuming the unfamiliar species. This fear for edible insects amongst insect eating communities is apparent in the fact that while most edible insects are available in all communities, what is classified as "edible" varies from one community to another.

Consumer reluctance and willingness to consume edible insects is one of the biggest barriers to integration of edible insects as food and feeds (Palmieri et al. 2019). Previous studies have indicated that consumers' reluctance to try unfamiliar foods (food neophobia), is a key determinant of their rejection of novel foods like edible insects (Fenko et al. 2015; Hartmann 
et al. 2015; Sogari et al. 2019). For instance, La Barbera et al. (2018) and Mancini et al. (2019) showed that both insect food disgust and food neophobia were strong determinants of intention to consume insect-based products. In addition, Lombardi et al. (2019) revealed that food neophobia and attitude negatively affected willingness to pay for edible insects. These studies on the relationship between food neophobia and consumption of edible insects, have mainly been conducted in countries where insects are not traditionally consumed. However, the aversion and neophobia towards edible insects vary across population (Verbeke 2015), even in countries where insects are traditionally consumed, because the insects considered as edible vary from one culture to another. Fischer and Steenbekkers (2018) found significant differences in willingness to consume different insect species, implying that general neophobia and attitude towards eating of insects, should not be the only consideration when investigating willingness to consume specific insects.

While literature on edible insects is rich with information on their nutritional composition and environmental benefits (Fombong et al. 2017; Kinyuru et al. 2013; Köhler et al. 2020; Rumpold and Schlüter 2013), there are still relatively few studies on consumer fear and consumption of edible insects and edible insect based foods, especially in the context of African consumers. Recent studies have made some attempts to understand the drivers of willingness to consume insects and insect-based food products but literature is still limited and inconclusive on the topic. In addition, most consumer-focused studies have been carried out amongst edible insect consumers in high income countries who are not traditional edible insect consumers such as Italy, Belgium, Germany and many western countries (Gere et al. 2017; Hartmann et al. 2015; La Barbera et al. 2018; Lombardi et al. 2019; Megido et al. 2016; Verbeke 2015). As such, very few studies exist on consumer fear and acceptance of edible insects in traditional insect consuming communities in low income countries (Alemu et al. 2017b; Ebenebe et al. 2017; Pambo et al. 2018). Additionally, the dynamics of consumer fear and consumption of edible insects may differ between developing and developed countries (Raheem et al. 2019). These differences could arise due to variation in food choices and differences in culture. These differences are apparent in the available limited literature which show a positive preference and perception towards insect and insect-based foods in developing countries than in developed countries (Hartmann et al. 2015; Raheem et al. 2019). For instance, Alemu et al. (2017a) and Homann et al. (2017) reported positive preferences for cricket-based flour and biscuits amongst Kenyan adult consumers and school children, respectively; while Verbeke (2015) showed that only about one out of five (19.3\%) of Belgian meat consumers were ready to adopt insects as 
food. Further, according to Schouteten et al. (2016), insect-based burgers obtained a lower overall liking compared to meat based burgers among Belgian participants.

The current study therefore aimed to assess the influence of food neophobia and socio-cultural factors on the consumption and consumers' willingness to consume edible insects. By focusing on three most commonly consumed edible insects in Uganda; the long-horned grasshoppers (Ruspolia differens), the flying African termites (Macrotermes bellicosus), and the red wingless termites (Macrotermes spp), the study makes three key contributions to edible insect consumption literature. First, it assesses the contribution of consumer personal attributes (e.g. level of food neophobia) to consumption and willingness to consume edible insects; second, it investigates the effect of cultural differences on the consumption of edible insects; and third, it compares factors that determine consumption of the three most common edible insect species in Uganda.

\section{Materials and methods}

\section{Study setting}

The study was conducted in two districts of Wakiso (Central Uganda) and Adjumani (Northern Uganda). Entomophagy is an important part of culture in Uganda and provides significant nutritional and economic benefits to rural communities (Odongo et al. 2018). The most commonly consumed edible insects in Uganda include; termites (Macrotermes spp) and grasshoppers (Ruspolia differens) (Mbabazi 2012; Okia et al. 2017; Raheem et al. 2019). Macrotermes bellicosus, commonly called white ants (the winged form that swarm from termite hills) is the most common species of edible termites in Uganda. The ants are a delicacy in many communities especially in Northern Uganda where they are prepared and consumed in various forms including roasting, boiling, drying and pounding into paste that is mixed with peanut or sesame paste. The red wingless termites are currently consumed by only a small proportion of people across Uganda. The long horned grasshoppers, locally known in Uganda as nsenene (Ruspolia differens), are also consumed in many parts of the country, albeit it being more common in central Uganda (Agea et al. 2008; Okia et al. 2017). Culturally, the consumption of $R$. differens is usually associated with the Bantu ethnic group where it derives its common name, nsenene. However, there is a recent spread in consumption to other regions that did not traditionally consume the R.differens, including Northern Uganda. Even though the two termite species and the long horned grasshoppers, are the most commonly consumed insects in Uganda, 
others insect species such as crickets, cricket larvae, bee larvae, and locusts are also consumed in the country .

\section{Sampling design}

A multistage sampling approach was employed in this study. The study districts were purposively selected based on the relative abundance and consumption of edible insects under investigation. The Ruspolia differens is more abundant and predominantly consumed in the central region of Uganda. On the other hand, consumption of termites is predominant in Northern Uganda. From each district, two sub-counties were randomly selected from the list of sub-counties. The selection of study villages from the sub-counties was also randomly carried out. Finally, the households were selected systematically from the list of households in the villages by considering every fifth household on the list. Therefore, a total of 310 households were surveyed in the two districts. Only one adult (18 years and above) was interviewed per household.

\section{Data collection}

A structured household questionnaire was used to collect data. The questionnaire was pre-tested both in Gulu (Northern Uganda) and Kampala (Central Uganda) districts and later administered through face to face interviews in the local languages of the two selected districts by trained research assistants. The interviewers were trained in a central location (Gulu University) and met to discuss the pre-tested questionnaire before conducting the interviews in the respective study locations. The research assistants and field supervisors met daily to check the completed questionnaires. Before starting the interview, the research assistants introduced themselves, welcomed the participants and introduced to them the objectives of the study. The respondents then gave their consent after the consent information was read to them. Data were collected on participants demographic information (e.g. age, gender, education, occupation), food neophobia, familiarity with and willingness to consume edible insects.

Consumer fear to consume novel food products like edible insects can be studied using the food neophobia scale (FNS) (Kallas et al. 2019; Pliner and Hobden 1992). The participants' expressions of food neophobia was assessed using the 10-statements food neophobia scale (FNS) (Pliner and Hobden 1992) as shown in Table 1. Participants answered each of the FNS questions on a 5-point Likert scale ( $1=$ strongly disagree, $5=$ strongly agree). Some studies have applied a 7-point Likert scale in responding to FNS questions (Mustonen et al. 2012; Olabi et al. 2009) while others used a 5-point scale (Barrena and Sánchez 2013; Gere et al. 2017). A lower preference rating scale like 5-point scale has been found easier and relatively quicker to 
use, compared to higher scales like 7-point and 9-point scales (Damsbo-Svendsen et al. 2017; Preston and Colman 2000), justifying our preference for the former in the current study.

Questions on familiarity with and willingness to consume the three edible insects under study were framed based on previous studies (Olabi et al. 2009; Verneau et al. 2014). Participants were first asked how familiar each of the insects was to them. They could respond to this question by selecting one of the five responses; 1) "I don't know the insect", 2) "I know but I have never tasted it", 3) "I have tasted but I did not like it", 4) "I occasionally eat it or its products" and 5) "I regularly eat the insect or its products". Those who had not eaten the insects were asked if they would consider eating them in future, and could respond with a yes or no. The food familiarity scale is a valuable tool as it can be easily converted into consumption behaviour, depending on the level of familiarity with a particular food (Verneau et al. 2014). In the current study, the first two responses (I don't know the insect and I know but I have never tasted it) were re-coded to represent one variable (not consumed/tasted the edible insect at the time of the study) and the last three responses were re-coded into previously consumed the edible insect. This approach has been used in a similar research work by Olabi et al. (2009).

\section{Statistical analysis}

As food neophobia is a negative feeling towards novel foods, responses to positively framed questions of the FNS were reversed during analysis. The score of the food neophobia for each participant was calculated by taking the sum of the scores of 10 FNS questions and could range from 10 to 50. Cronbach's alpha was used to test for the internal consistency of the FNS and maximum likelihood factor analysis method with Varimax rotation was applied to verify if the FNS items were unidimensional or if they would load on multiple factors. Further, Pearson's correlation was applied to assess the relationship between food neophobia and continuous variables like age and household size. Univariate statistics were the basis to test the variation of food neophobia with categorical variables, while accounting for the assumptions of normality and homoscedasticity. All explanatory variables were assessed for multi-collinearity based on the Variance Inflation Factor (VIF), and all were below 10 so none was found to violet this assumption. Hence all were included in the models evaluated.

The insect familiarity question was transformed into a consumption variable, classifying participants into a group that consumed and the one that did not consume each of the insects under investigation. Thereby, given the nature of the outcome variable i.e. dichotomous, binary logistic regression analysis was applied to identify determinants (i.e. neophobia and socioeconomic factors) that are independently associated with consumption for each of the three 
insects. The two explanatory variables that were not originally of dichotomous nature were transformed in to dummy variables for easy interpretation as well as to reduce the number of empty cells. Thereby, for marital status, the married category was compared with single, widowed and divorced as one group. For education, no education and primary level categories were combined against secondary and higher education. However, for occupation the four original categories (i.e. unemployed, self-employed, civil servant and pensioner were transformed and reduced to three categories (i.e. unemployed, self-employed and employed), with the employed category combining civil servant and pensioner. Statistical significance was assumed at $\mathrm{p}<0.05$ and all determinants were in the end included in the final models regardless of their performance in univariate comparisons.

Given that only a small proportion of participants had consumed the red wingless termites, the same analysis was further applied to predict future consumption of red termites among the nonconsumers at the time of the study. For grasshoppers and flying termites (macrotermes belicosus), future consumption was not predicted since majority of participants reported to have consumed them. For all models, results are presented and reported in form of odd-ratios to facilitate interpretation of obtained coefficients.

\section{Results}

\section{Characteristics of edible insect consumers}

The description of study sample is presented in Table 1, along with the proportions that had consumed each of the three edible insects studied. There was no significant variation in the consumption of the long-horned grasshoppers in the two study regions while there was a significant variation in the consumption of the two species of termites (white ants and red termites) across the regions. Further there was a significant variation in the ages of consumers and non-consumers of the long-horned grasshoppers, with consumers tending to be younger (34.7 \pm 12.7 years) compared to the non-consumers $(40.7 \pm 16.5$ years $)$. Age did not significantly vary among the consumers and non-consumers of the two species of termites. Marital status (with majority being married), education (majority with at least a secondary level education) and occupation (with majority self-employed in private businesses and farms), did not significantly vary among consumers and non-consumers of the three edible insects studied. Majority of the respondents resided in households with more than 5 persons and the household size varied significantly only among the consumers and non-consumers of red termites but not the other two insect species. Finally, the level of food neophobia was high irrespective of 
previous reported consumption of the insects studied. The detailed description of the study sample can be seen in Table 1.

\section{[Table 1 here]}

\section{The food neophobia scores}

The responses to the different statements of the FNS are presented in Table 2. The Cronbach's alpha score of 0.78 indicate a good reliability of the FNS statements. However, the 10 FNS items were not unidimensional for our study sample as the items loaded on three factors. Items 5 and 10 which are related to the reluctance to try ethnic foods loaded on factor 3 while items 4 and 6 loaded on factor 2, depicting the reluctance to try new foods. The rest of the items loaded on factor 1 and seem to be related to consumers' lack of trust in unfamiliar (novel) foods (Table 2). Lack of unidimensional FNS have been reported in previous studies (Choe and Cho 2011; Hartmann et al. 2015; Olabi et al. 2009) conducted in different cultural contexts. A study in Kenya applied 6 of the 10 items of the FNS, modified to suit the cultural situation in Kenya (Alemu et al. 2017b) and also did not achieve a unidimensional scale. We opted for the original 10 item FNS as many studies have already applied the original scale in different cultural settings which would enable some comparison with our results. In addition, our study acted as a validation for the original FNS in a Ugandan setting as there are limited studies in Africa that have investigated the relationship between food neophobia and consumption of novel foods using the original 10-item FNS.

The mean score to the questions of the FNS on a scale of 1-5 was high (34.19 out of 50) suggesting that consumers tended to agree with the statements, indicating a high likelihood of being food neophobic (high level of fear for novel foods). Out of the 310 respondents, 174 of them $(56.1 \%)$ had FNS scores greater than the mean score of 34.19 and 136 (43.9\%) presented FNS scores lower than the mean. Thereby, more than half of our study participants can be classified as being more food neophobic based on the FNS scores above the mean.

\section{[Table 2 here]}

\section{Relationship between food neophobia and socio-cultural characteristics}

Results in Table 3 show that consumers from Northern Uganda generally had a significantly higher level of food neophobia compared to those from the central region, while female participants had a higher food neophobia than their male counterparts. We also observed a significant positive relationship between food neophobia and age of participants, showing that food neophobia increased with age. Furthermore, there was a significant variation in food 
neophobia among the different categories of occupation and education, with notable higher levels of neophobia among those with lower levels of education as well as unemployed participants. Food neophobia did not vary significantly between the married and unmarried respondents and had no significant association with household size (Table 3).

\section{[Table 3 here]}

Further, Figure 1 shows the variation in the food neophobia scores of consumers and nonconsumers of the three edible insects in the two study locations. Participants from Northern Uganda showed high level of food neophobia irrespective of being consumers or nonconsumers of the edible insects. This is contrary to the participants from central Uganda, where non-consumers of grasshoppers and white ants were more food neophobic compared to consumers of the same. However, this trend was reversed for consumers and non-consumers of red termites in the central region (Figure 1).

[Figure 1 here]

\section{The effect of food neophobia and socio-cultural factors on edible insect consumption}

Table 4 presents results from the logistic regression of the influence of socio-cultural factors and food neophobia on consumption of the three edible insects. There was a significant effect of location on the consumption of all the three edible insects, with the consumption of the longhorned grasshoppers and white ants being more likely in Northern compared to Central Uganda. Age had a significant positive effect on consumption of only the long-horned grasshoppers. Education also had a significant effect on consumption of only long-horned grasshoppers with participants having secondary and higher-level education, less likely to consume the insect compared to those with lower levels of education. Food neophobia had a significant effect on consumption of the two-termite species but not on consumption of long-horned grasshoppers. Thereby, participants with higher scores of food neophobia are almost $10 \%$ less likely to consume white ants. Surprisingly, the opposite was true with high neophobic participants exhibiting a higher likelihood to consume red termites.

\section{[Table 4 here]}

Given that only a low proportion of participants had consumed red termites (Table 1), we further analysed the factors that could predict future consumption (willingness to consume) of red termites amongst non-consumers. The results presented in Table 4, shows that only location significantly predicts willingness to consume red termites at $5 \%$ level of significance. Thereby, participants in Central Uganda are $60 \%$ less likely to consume red termites in future, compared to those from the Northern region. The effect of food neophobia on future consumption of red 
termites is only significant at $10 \%$ and with an odds ratio of 0.96 , showing that those with higher neophobia are less likely to consume the red termites in future.

\section{Discussions}

The aim of this study was to evaluate the effects of socio-cultural factors and food neophobia on consumption and willingness to consume edible insects. The study population generally had high levels of food neophobia. This result is in agreement with a previous study in which Ugandan consumers were shown to exhibit high levels of neophobia towards foods produced by novel technologies (De Steur et al. 2016). Education, and age were the significant personal characteristics that influenced the level of food neophobia amongst consumers. Consumers with higher levels of education had lower levels of food neophobia than the uneducated consumers, while older consumers tended to be more neophobic than younger ones. A similar trend of significance of education on food neophobia has been reported in previous studies (Mustonen et al. 2012; Vidigal et al. 2015). The observed influence of education on food neophobia can be explained by the conservativeness and food cultural embeddedness that exist amongst most Ugandan consumers. While educated consumers get exposed as they move out of their cultural settings in search of employment opportunities, uneducated consumers tend to remain embedded in their cultural settings and hence cultural foods. As a result, educated consumers may often get exposed to and try new foods hence the low level of food neophobia. On the other hand, uneducated consumers, who remain living and embedded in their cultural setting, and hence food, are more likely to be averse to unfamiliar/new foods. Consequently, new/foreign foods to which they are unfamiliar tend to be perceived negatively. Thus, to reduce the level of neophobia towards novel foods like edible insects, it might be necessary to increase the level of knowledge of consumers about the nutritional and health benefits of such edible insects' consumption. The high food neophobia amongst older consumers can be explained by the fact that older consumers tend to be risk averse, and hence less interested and cautious in trying out new foods. They would prefer to stick with foods that are familiar to them, which to them are safer (Vidigal et al. 2015). On the other hand, younger consumers tend to be more adventurous, trying out novel foods, hence the low level of food neophobia.

We find that consumers' level of food neophobia, location, and age influenced their consumption of edible insects. Consumers with high levels of food neophobia were less likely to consume edible insects that were not consumed in their region, hence not familiar or new to them. In the study of Sogari et al. (2019), participants with high levels of food neophobia were also less likely to consume insect products. A similar result was found in the study of La Barbera 
et al. (2018). In the current study, consumers in central Uganda were more neophobic towards termites than to grasshoppers. Although consumption of edible insects is widespread in Uganda, the type of edible insects consumed varies between the different regions and cultures. For instance, the Bantu ethnic group, who occupies the central region of Uganda predominantly consumes grasshoppers (Agea et al. 2008), while the Nilotics (who occupy the northern region) majorly consumes termites and their alates (Akullo et al. 2017). The study of Akullo et al. (2017), conducted in Lango sub-region of Northern Uganda showed that over 90\% of the participants consumed white ants, a finding that compares well with results from the current study. This observation could explain the observed effect of location on consumption of insects and justifies the influence of culture and familiarity on edible insect consumption.

The importance of familiarity is further underpinned by the observation that food neophobia did not affect the consumption of long-horned grasshoppers across the regions, but affected the consumption of termites. Although grasshoppers are not a traditional edible insect in northern Uganda, consumers did not show high neophobia towards it. This can be attributed to the wide spread, and hence consumption of grasshoppers throughout Uganda (Agea et al. 2008; Okia et al. 2017). In fact, it is currently common to get roasted or deep fried grasshoppers being sold in northern Uganda (Odongo et al. 2018). However, the same cannot be said of termites, whose consumption remains confined to particular regions and cultures. This observation suggests that improving awareness and hence familiarity could improve consumers' acceptance and eventual consumption of edible insects to break regional and cultural boundaries. A study comparing perceptions of consumers in Korea and Ethiopia on consumption of insects advanced history and familiarity with insects as the major reasons for the observed differences among consumers from the two countries (Ghosh et al. 2020), further indicating the importance of familiarity on consumers' consumption of insects.

The influence of culture and familiarity is further reinforced when looking at the potential future consumption for the red termites. While, the probability of future consumption amongst central Ugandan consumers was low, northern consumers exhibited high probability of future consumption. Consumption of red termites in northern Uganda is not a new phenomenon to consumers, as consumption has been reported in previous study (Akullo et al. 2017). Only that, red termites are consumed during periods of food scarcity as a hunger coping strategy, since they are not seasonal and can be easily harvested from anthills. This makes it easy for northern Ugandan consumers to imagine the possibility of consuming it in the future. To the contrary, central Uganda consumers are not familiar with red termite consumption and as such it is difficult for them to imagine consuming it in the future. It is also important to note that the red 
termites are actually a wingless form of the winged termites (white ants), reportedly consumed to a greater extent in northern Uganda. This observation also suggests that previous experience in consumption of an edible insect has an effect on determining future consumption (Megido et al. 2016). This has implications on the future of insect-based foods products as consumers will most likely consume products based on specific insects or related species they consume or have consumed in the past. The role of familiarity on consumption of edible insects has important implications for the development and promotion of edible insects and insect based products. Development and promotional efforts should be context specific, targeting culturally acceptable edible insects while at the same time navigating possibilities to penetrate market segments perceived as unaccepting to a particular edible insect.

Additionally, we observe that personal factors including education and age were significant indicators of consumption of edible insects. These personal variations have been reported in past studies to influence edible insect consumption among African consumers (Alemu et al. 2017b; Anankware et al. 2017; Pambo et al. 2018). Generally, younger people are often more willing to try new foods compared to the older ones (Lombardi et al. 2019), which is why our analysis showed that the older people were less likely to consume the long-horned grasshoppers. The result that shows that people with higher level of education were less likely to consume the long-horned grasshoppers is somewhat surprising, as we have shown that the educated consumers were less food neophobic compared to less educated participants. This could be related to other food preference issues, not assessed in the current study.

\section{Conclusions}

This study shows that present and future edible insect consumption is influenced by culture and food neophobia. While neophobia influenced current consumption, we observed that future edible insects' consumptions can be influenced by culture and familiarity. We find evidence of variations in edible insects' consumption and willingness to consume between the study regions and culture. While the long-horned grasshoppers were accepted and consumed in both regions, the two termite species were mainly preferred in Northern and not in Central Uganda. The major reasons for the observed variations in edible insect consumption can be attributed to cultural differences and hence familiarity with particular edible insects. However, personal factors such as level of education, and age also influenced edible insects consumption preference. Regarding food neophobia, we find that neophobic consumers were less likely to consume edible insects which are not familiar to them. On the other hand, food neophobia was not a significant 
predictor of future consumption of edible insects, suggesting that familiarity, other than neophobia is what may affect future edible insect consumption.

Results from this study suggests that promotion of edible insect consumption should be based on familiarity of consumers with specific edible insects, and culture which depends on the location of the consumers. In addition, personal characteristics of consumers have to be considered. Considering the three edible insects studied, consumption seem more likely among young, educated and less food neophobic consumers.

For policy makers, promoting edible insects' consumption will require focusing on awareness creation and advocacy targeting specific cultures. This is because culture and familiarity are important parameters in consumers' decision to consume edible insects. Given the nascent recognition of insects as alternative sources of cheap protein for healthy diets, our study represents a basis for future push and introduction of this food-based nutrition strategy in Uganda and similar contexts. Results of this study can therefore be used to develop plans and strategies for promotion of insect-based products in Uganda and other developing countries. To this effect, future research that amplifies the role or contribution of edible insects to diets should be promoted so as to influence nutritional policy and practices.

Much as this paper highlights the influence of neophobia and culture on the consumption of insects in Uganda, the study only focused on the consumption of three edible insect species in two cultural settings. Consequently, application of the findings should be done with caution beyond these contexts. Future studies could therefore look at understanding the influence of culture and food neophobia in other contexts and cultures to corroborates our findings. Such studies could also be done in communities that traditionally consume edible insects in Africa.

Conflict of Interest: The authors declare that they have no conflict of interest. 


\section{References}

Agea JG, Biryomumaisho D, Buyinza M, Nabanoga GN (2008) Commercialization of Ruspolia nitidula (nsenene grasshoppers) in central Uganda African Journal of Food, Agriculture, Nutrition and Development 8:319-332

Akullo J, Obaa B, Acai JO, Nakimbugwe D, Agea J (2017) Knowledge, attitudes and practices on edible insects in Lango sub-region, northern Uganda Journal of Insects as Food and Feed 3:73-81

Alemu MH, Olsen SB, Vedel SE, Kinyuru JN, Pambo KO (2017a) Can insects increase food security in developing countries? An analysis of Kenyan consumer preferences and demand for cricket flour buns Food Security 9:471-484

Alemu MH, Olsen SB, Vedel SE, Pambo KO, Owino VO (2017b) Combining product attributes with recommendation and shopping location attributes to assess consumer preferences for insectbased food products Food Quality and Preference 55:45-57

Anankware P, Osekre E, Obeng-Ofori D, Khamala C (2017) Factors that affect entomophagical practices in Ghana Journal of Insects as Food and Feed 3:33-41

Barrena R, Sánchez M (2013) Neophobia, personal consumer values and novel food acceptance Food quality and preference 27:72-84

Choe JY, Cho MS (2011) Food neophobia and willingness to try non-traditional foods for Koreans Food Quality and Preference 22:671-677

Clune S, Crossin E, Verghese K (2017) Systematic review of greenhouse gas emissions for different fresh food categories Journal of Cleaner Production 140:766-783

Coleman DP (2016) Toothsome Termites and Grilled Grasshoppers: A cultural history of invertebrate gastronomy Animal Studies Journal 5:1-22

Collavo A, Glew RH, Huang Y-S, Chuang L-T, Bosse R, Paoletti MG (2005) House cricket small-scale farming Ecological implications of minilivestock: potential of insects, rodents, frogs and snails 27:515-540

Damsbo-Svendsen M, Frøst MB, Olsen A (2017) A review of instruments developed to measure food neophobia Appetite 113:358-367

De Steur H, Odongo W, Gellynck X (2016) Applying the food technology neophobia scale in a developing country context. A case-study on processed matooke (cooking banana) flour in Central Uganda Appetite 96:391-398

Ebenebe CI, Amobi MI, Udegbala C, Ufele A, Nweze B (2017) Survey of edible insect consumption in south-eastern Nigeria Journal of Insects as Food and Feed 3:241-252

Fenko A, Backhaus BW, van Hoof JJ (2015) The influence of product- and person-related factors on consumer hedonic responses to soy products Food Quality and Preference 41:30-40 doi:https://doi.org/10.1016/j.foodqual.2014.11.009

Fischer AR, Steenbekkers LB (2018) All insects are equal, but some insects are more equal than others British food journal

Fombong FT, Van Der Borght M, Vanden Broeck J (2017) Influence of freeze-drying and oven-drying post blanching on the nutrient composition of the edible insect Ruspolia differens Insects 8:102

Gere A, Székely G, Kovács S, Kókai Z, Sipos L (2017) Readiness to adopt insects in Hungary: A case study Food Quality and Preference 59:81-86 doi:https://doi.org/10.1016/j.foodqual.2017.02.005

Ghosh S, Jung C, Meyer-Rochow V, Dekebo A (2020) Perception of entomophagy by residents of Korea and Ethiopia revealed through structured questionnaire Journal of Insects as Food and Feed 6:59-64

Hartmann C, Shi J, Giusto A, Siegrist M (2015) The psychology of eating insects: A cross-cultural comparison between Germany and China Food Quality and Preference 44:148-156 doi:https://doi.org/10.1016/j.foodqual.2015.04.013

Homann A, Ayieko MA, Konyole S, Roos N (2017) Acceptability of biscuits containing $10 \%$ cricket (Acheta domesticus) compared to milk biscuits among 5-10-year-old Kenyan schoolchildren Journal of Insects as Food and Feed 3:95-103

Kallas Z, Vitale M, Gil JM (2019) Health innovation in patty products. the role of food neophobia in consumers' non-hypothetical willingness to pay, purchase intention and hedonic evaluation Nutrients 11:444 
Kelemu S et al. (2015) African edible insects for food and feed: inventory, diversity, commonalities and contribution to food security Journal of Insects as Food and Feed 1:103-119

Kinyuru JN et al. (2013) Nutrient composition of four species of winged termites consumed in western Kenya Journal of food composition and analysis 30:120-124

Köhler R, Irias-Mata A, Ramandey E, Purwestri R, Biesalski HK (2020) Nutrient composition of the Indonesian sago grub (Rhynchophorus bilineatus) International Journal of Tropical Insect Science:1-10 doi:10.1007/s42690-020-00120-z

La Barbera F, Verneau F, Amato M, Grunert K (2018) Understanding Westerners' disgust for the eating of insects: The role of food neophobia and implicit associations Food Quality and Preference 64:120-125 doi:https://doi.org/10.1016/j.foodqual.2017.10.002

Lombardi A, Vecchio R, Borrello M, Caracciolo F, Cembalo L (2019) Willingness to pay for insectbased food: The role of information and carrier Food quality and preference 72:177-187

Mancini S, Sogari G, Menozzi D, Nuvoloni R, Torracca B, Moruzzo R, Paci G (2019) Factors predicting the intention of eating an insect-based product Foods 8:270

Mbabazi M Edible insects in Eastern and Southern Africa: challenges and opportunities. In: Barbara B, Sandro D (eds) SUSTAINABLE DIETS AND BIODIVERSITY, FAO Headquarters, Rome, 2012. FAO,

Megido RC, Gierts C, Blecker C, Brostaux Y, Haubruge É, Alabi T, Francis F (2016) Consumer acceptance of insect-based alternative meat products in Western countries Food Quality and Preference 52:237-243

Mustonen S, Oerlemans P, Tuorila H (2012) Familiarity with and affective responses to foods in 8-11year-old children. The role of food neophobia and parental education Appetite 58:777-780

Odongo W, Okia C, Nalika N, Nzabamwita P, Ndimubandi J, Nyeko P (2018) Marketing of edible insects in Lake Victoria basin: the case of Uganda and Burundi Journal of Insects as Food and Feed 4:285-293

Okia C, Odongo W, Nzabamwita P, Ndimubandi J, Nalika N, Nyeko P (2017) Local knowledge and practices on use and management of edible insects in Lake Victoria basin, East Africa Journal of Insects as Food and Feed 3:83-93

Olabi A, Najm NEO, Baghdadi OK, Morton JM (2009) Food neophobia levels of Lebanese and American college students Food Quality and Preference 20:353-362

Palmieri N, Perito MA, Macrì MC, Lupi C (2019) Exploring consumers' willingness to eat insects in Italy British Food Journal

Pambo KO, Okello JJ, Mbeche RM, Kinyuru JN, Alemu MH (2018) The role of product information on consumer sensory evaluation, expectations, experiences and emotions of cricket-flourcontaining buns Food Research International 106:532-541

Pliner P, Hobden K (1992) Development of a scale to measure the trait of food neophobia in humans Appetite 19:105-120

Preston CC, Colman AM (2000) Optimal number of response categories in rating scales: reliability, validity, discriminating power, and respondent preferences Acta psychologica 104:1-15

Raheem D, Carrascosa C, Oluwole OB, Nieuwland M, Saraiva A, Millán R, Raposo A (2019) Traditional consumption of and rearing edible insects in Africa, Asia and Europe Critical reviews in food science and nutrition 59:2169-2188

Roos N, Van Huis A (2017) Consuming insects: are there health benefits? Journal of insects as food and feed 3:225-229

Rumpold BA, Schlüter OK (2013) Nutritional composition and safety aspects of edible insects Molecular nutrition \& food research 57:802-823

Schouteten JJ et al. (2016) Emotional and sensory profiling of insect-, plant-and meat-based burgers under blind, expected and informed conditions Food Quality and Preference 52:27-31

Smetana S, Mathys A, Knoch A, Heinz V (2015) Meat alternatives: life cycle assessment of most known meat substitutes The International Journal of Life Cycle Assessment 20:1254-1267

Sogari G, Menozzi D, Mora C (2019) The food neophobia scale and young adults' intention to eat insect products International Journal of Consumer Studies 43:68-76 doi:10.1111/ijcs.12485

Steinfeld H, Gerber P, Wassenaar T, Castel V, Rosales M, Rosales M, de Haan C (2006) Livestock's long shadow: environmental issues and options. Food \& Agriculture Org., 
Tilman D, Clark M (2014) Global diets link environmental sustainability and human health Nature 515:518-522

United Nations DoEaSA, Population Division (2017) World Population Prospects: The 2017 Revision, Key Findings and Advance Tables. Working Paper No. ESA/P/WP/248. United Nations, New York, USA

Van Huis A, Van Itterbeeck J, Klunder H, Mertens E, Halloran A, Muir G, Vantomme P (2013) Edible insects: future prospects for food and feed security. vol 171. FAO, Rome

Vanhonacker F, Van Loo EJ, Gellynck X, Verbeke W (2013) Flemish consumer attitudes towards more sustainable food choices Appetite 62:7-16

Verbeke W (2015) Profiling consumers who are ready to adopt insects as a meat substitute in a Western society Food Quality and Preference 39:147-155

Verneau F, Caracciolo F, Coppola A, Lombardi P (2014) Consumer fears and familiarity of processed food. The value of information provided by the FTNS Appetite 73:140-146

Vidigal MC, Minim VP, Simiqueli AA, Souza PH, Balbino DF, Minim LA (2015) Food technology neophobia and consumer attitudes toward foods produced by new and conventional technologies: A case study in Brazil LWT-Food Science and Technology 60:832-840 
Tables

Table 1: Variation in socio-demographic characteristics of study samples $(n=310)$, segregated by their insect consumption statuses

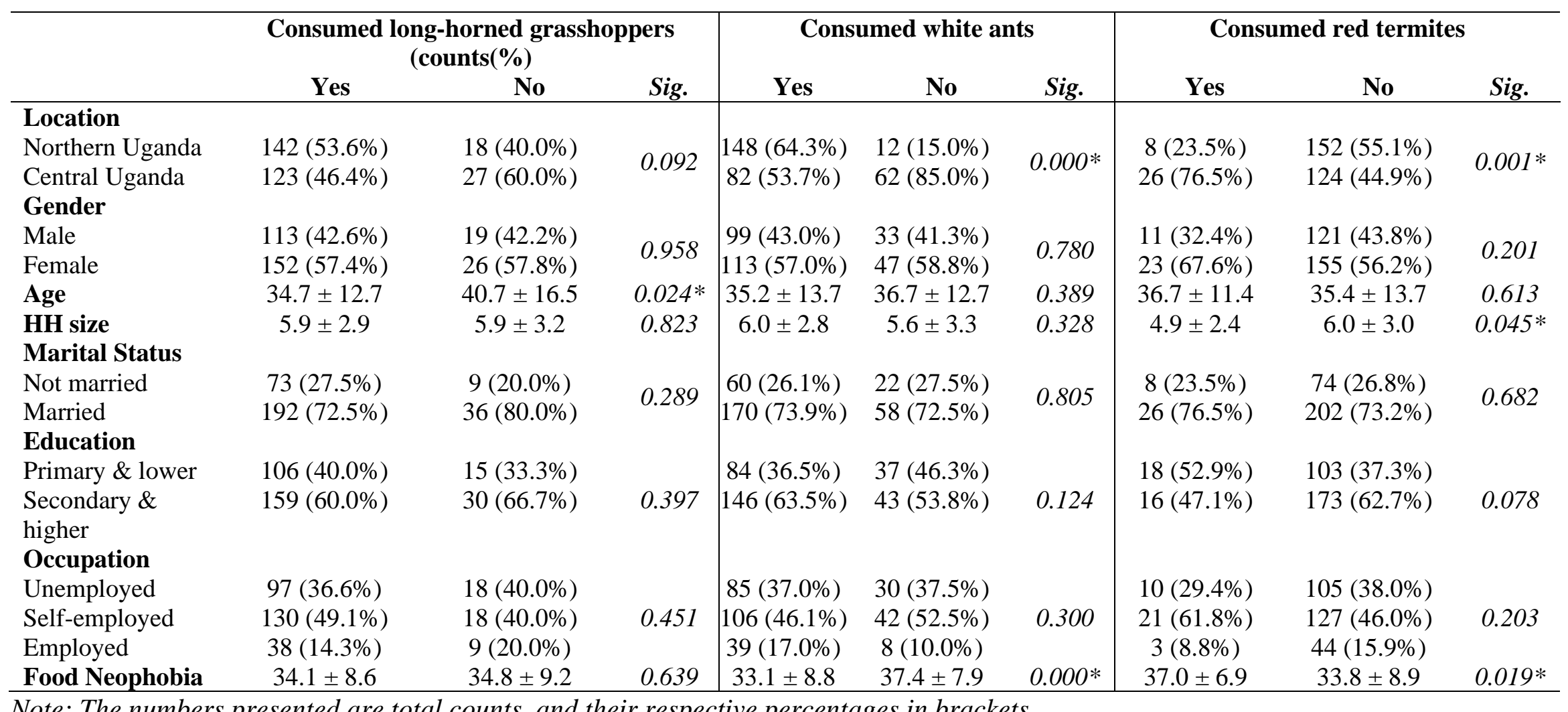


Table 2: Description of food neophobia scale item mean and standard deviation and Varimax rotated factor matrix values.

\begin{tabular}{llrrrrr}
\hline Item & Mean & SD & Factor 1 & Factor 2 & Factor 3 \\
\hline 1 & I am constantly sampling new and different foods $(\mathbf{R})$ & 3.63 & 1.508 & $\mathbf{0 . 5 2 4}$ & 0.276 & 0.106 \\
2 & I don't trust new foods & 3.94 & 1.415 & $\mathbf{0 . 7 3 3}$ & 0.255 & -0.031 \\
3 & If I don't know what is in a food, I will not try it & 4.02 & 1.411 & $\mathbf{0 . 6 3 5}$ & 0.210 & -0.049 \\
4 & I like foods from different countries $(\mathbf{R})$ & 2.89 & 1.602 & 0.254 & $\mathbf{0 . 6 7 3}$ & -0.035 \\
5 & Ethnic food looks weird to me & 2.28 & 1.589 & -0.120 & -0.009 & $\mathbf{0 . 9 9 2}$ \\
6 & At dinner parties, I will try new food $(\mathbf{R})$ & 2.95 & 1.566 & 0.181 & $\mathbf{0 . 6 2 6}$ & 0.068 \\
7 & I am afraid to eat things I have never had before & 4.08 & 1.384 & $\mathbf{0 . 6 5 9}$ & 0.113 & 0.069 \\
8 & I am very particular about the foods I will eat & 3.85 & 1.396 & $\mathbf{0 . 6 8 2}$ & 0.163 & -0.059 \\
9 & I will eat almost anything $(\mathbf{R})$ & 4.12 & 1.356 & $\mathbf{0 . 5 9 2}$ & 0.217 & 0.001 \\
10 & I like to try new ethnic restaurants $(\mathbf{R})$ & 2.73 & 1.513 & 0.273 & 0.291 & $\mathbf{0 . 3 0 6}$ \\
\hline \multicolumn{2}{l}{ Reliability Cronbach's alpha) } & $\mathbf{0 . 7 8}$ & & & & \\
$\quad$ Mean score of FNS & $\mathbf{3 4 . 1 9}$ & 8.72 & & & \\
\hline
\end{tabular}

$*(\boldsymbol{R}):$ items are reverse-coded; Loadings that are highest on one of the three factors are bolded

Table 3: Relationships between level of food neophobia and population parameters $(n=310)$

\begin{tabular}{lccc}
\hline & \multicolumn{3}{c}{ Food neophobia score } \\
\cline { 2 - 4 } Parameter & Mean/correlation & SD & p-value \\
\hline Location & 35.9 & 6.5 & $0.000^{*}$ \\
$\quad$ Northern Uganda & 32.4 & 10.3 & \\
$\quad$ Central Uganda & 32.8 & & $0.012^{*}$ \\
Gender & 35.3 & 9.1 & $0.007^{*}$ \\
$\quad$ Male & 0.15 & 8.3 & 0.064 \\
$\quad$ Female & 0.11 & & 0.082 \\
Age & & & \\
HH size & 32.8 & 8.1 & $0.000^{*}$ \\
Marital Status & 34.7 & 8.8 & \\
$\quad$ Not married & & & $0.000^{*}$ \\
$\quad$ Married & 38.0 & 7.3 & \\
Education & 31.8 & 8.7 & \\
$\quad$ Primary \& lower & & & \\
$\quad$ Secondary \& higher & 36.6 & 7.7 & \\
Occupation & 34.0 & 9.1 & \\
$\quad$ Unemployed & 28.7 & 7.5 & \\
$\quad$ Self-employed & & & \\
$\quad$ Employed & & &
\end{tabular}




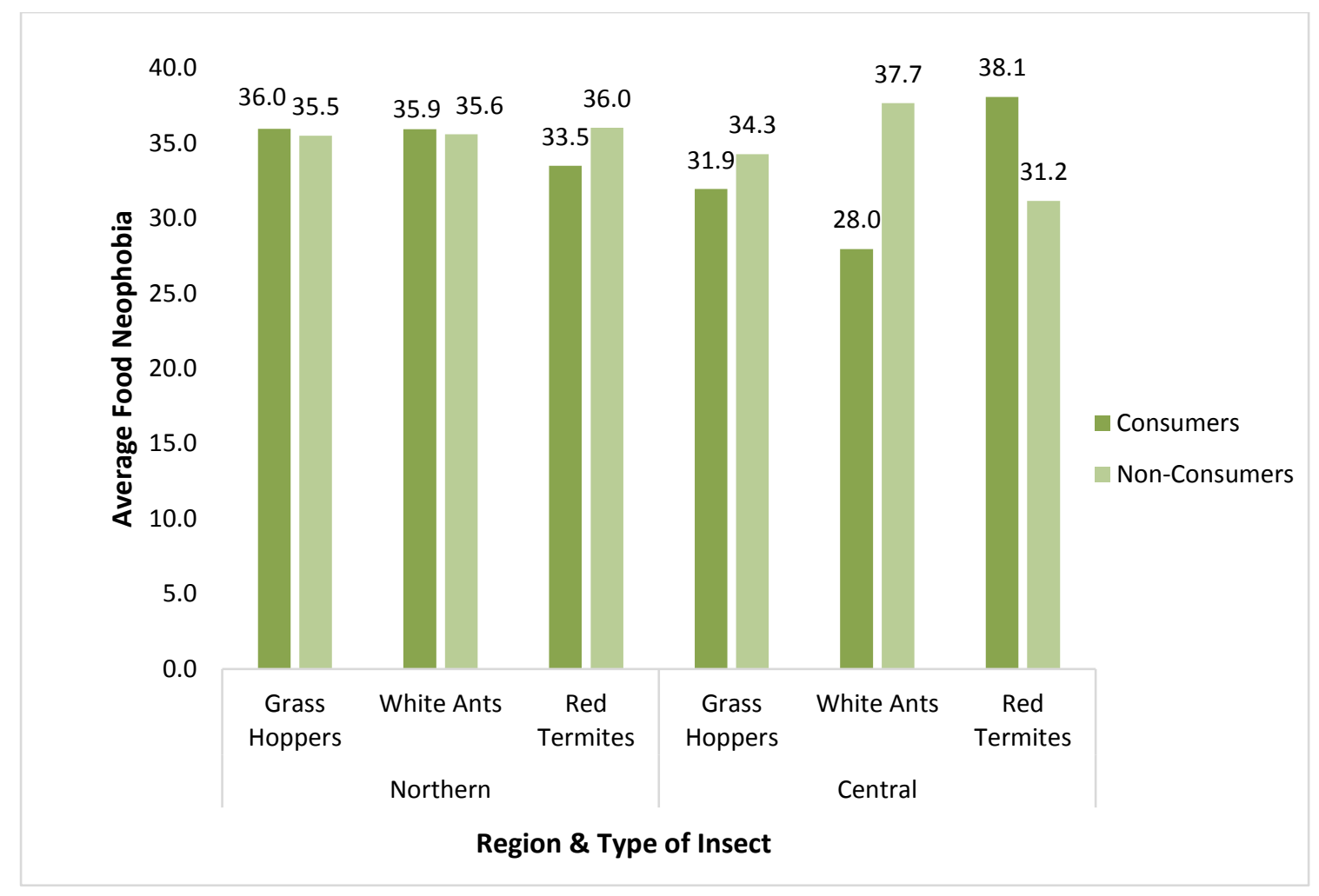

Figure Error! No text of specified style in document.1: Variation in the level of food neophobia among consumers and non-consumers of edible insects in Northern and Central Uganda 


\begin{tabular}{|c|c|c|c|c|c|c|c|c|c|}
\hline \multirow[t]{2}{*}{ Variables } & \multicolumn{3}{|c|}{ Model 1: Grasshoppers } & \multicolumn{3}{|c|}{ Model 2: White Ants } & \multicolumn{3}{|c|}{ Model 3: Red Termites } \\
\hline & OR & CI & Sig. & OR & CI & Sig. & OR & CI & Sig. \\
\hline $\begin{array}{l}\text { Location } \\
\text { Northern Uganda (Ref) } \\
\text { Central Uganda }\end{array}$ & $\begin{array}{c}1 \\
0.48\end{array}$ & $0.23-1.01$ & $0.052 *$ & $\begin{array}{c}1 \\
0.42\end{array}$ & $0.02-0.10$ & $0.000 *$ & $\begin{array}{c}1 \\
0.40\end{array}$ & $0.16-0.95$ & $0.039 *$ \\
\hline Gender & & & & & & & & & \\
\hline Male (ref) & 1 & & & 1 & & & 1 & & \\
\hline Female & 1.08 & $0.53-2.21$ & 0.826 & 1.50 & $0.76-3.00$ & 0.246 & 0.75 & $0.36-1.56$ & 0.444 \\
\hline Age & 0.96 & $0.94-0.99$ & $0.008 *$ & 1.01 & $0.98-1.14$ & 0.523 & 0.99 & $0.95-1.02$ & 0.468 \\
\hline HH size & 1.00 & $0.88-1.13$ & 0.963 & 0.92 & $0.81-1.03$ & 0.149 & 1.11 & $0.99-1.25$ & 0.073 \\
\hline $\begin{array}{l}\text { Marital Status } \\
\text { Not married (ref) } \\
\text { Married }\end{array}$ & $\begin{array}{c}1 \\
0.88\end{array}$ & $0.35-2.19$ & 0.782 & $\begin{array}{c}1 \\
1.00\end{array}$ & $0.45-2.24$ & 0.993 & $\begin{array}{c}1 \\
0.48\end{array}$ & $0.20-1.16$ & 0.104 \\
\hline $\begin{array}{l}\text { Education } \\
\text { Primary \& lower ( ref) } \\
\text { Secondary \& higher }\end{array}$ & $\begin{array}{c}1 \\
0.34\end{array}$ & $0.13-0.87$ & $0.024 *$ & $\begin{array}{c}1 \\
1.27\end{array}$ & $0.57-2.83$ & 0.559 & $\begin{array}{c}1 \\
0.717\end{array}$ & $0.28-1.81$ & 0.481 \\
\hline $\begin{array}{l}\text { Occupation } \\
\text { Unemployed (ref) } \\
\text { Self-employed } \\
\text { Employed } \\
\text { Food neophobia }\end{array}$ & $\begin{array}{c}1 \\
1.62 \\
1.08 \\
0.98\end{array}$ & $\begin{array}{l}0.73-3.60 \\
0.35-3.34 \\
0.94-1.02 \\
\end{array}$ & $\begin{array}{l}0.237 \\
0.897 \\
0.226 \\
\end{array}$ & $\begin{array}{l}1 \\
1.10 \\
0.44 \\
0.90\end{array}$ & $\begin{array}{l}0.54-2.26 \\
0.14-1.37 \\
0.86-0.94 \\
\end{array}$ & $\begin{array}{c}0.797 \\
0.154 \\
0.000 * \\
\end{array}$ & $\begin{array}{c}1 \\
0.96 \\
1.55 \\
0.96\end{array}$ & $\begin{array}{l}0.42-2.18 \\
0.53-4.56 \\
0.91-1.01 \\
\end{array}$ & $\begin{array}{l}0.914 \\
0.425 \\
0.083 \\
\end{array}$ \\
\hline
\end{tabular}

CI: confidence interval; OR: olds ratio; Models 1 and 2 analyse current consumption while model 3 predicts future consumption of edible insects;

* shows significant effect of the explanatory variable on the consumption or willingness to consume insects.

Collinearity: Location (1.20), Gender (1.15), Age (1.51), HH size (1.18), Marital status (1.35), Education (1.64), Occupation (1.30) \& Food neophobia (1.24) 